\title{
Enhancement of hydrolysis and acidification of solid organic waste by a rotational drum fermentation system with methanogenic leachate recirculation
}

\author{
Ling Chen ${ }^{\mathrm{a}}$, Wei Zhong Jiang ${ }^{\mathrm{a}^{*}}$, Yutaka Kitamura ${ }^{\mathrm{b}}$, Baoming Li ${ }^{\mathrm{a}}$ \\ ${ }^{a}$ College of Water Conservancy \& Civil Engineering, China Agricultural University, Beijing \\ 100083, China \\ ${ }^{\mathrm{b}}$ Graduate School of Life \& Environment Sciences, University of Tsukuba, 305-8572, Japan \\ ${ }^{*}$ Corresponding Author. Tel.: 86-10-62737992; fax: 86-10-62736413 \\ E-mail address: jiangwz@cau.edu.cn
}

\begin{abstract}
A cascade process of a rotational drum fermentation system with leachate recirculation from a methanogenesis to the acidogenic reactor was constructed to enhance the hydrolysis and acidification of solid organic waste. Using fresh soybean meal as substrates, two process configurations-Cascade process 1 and 2, without and with leachate recirculation, respectively-were employed to perform the experimental estimation under mesophilic condition and a total HRT of 20 days. An apparent first-order hydrolysis rate constant of $9.0 \times$ $10^{-3} / \mathrm{d}$ for Cascade process 1 at $\mathrm{pH}$ values of $4.5-4.6$ and $15.8 \times 10^{-3} / \mathrm{d}$ for Cascade process 2 at $\mathrm{pH}$ of 4.6-5.2, were obtained. The apparent VS degradation ratios ranged from $16.5 \%$ to 21.1\% and total VA (as acetic acid) from $14.5 \mathrm{~g} / \mathrm{L}$ to $16.7 \mathrm{~g} / \mathrm{L}$. Occupying ratios for ionized VA decreased from $40.5 \%$ to $35.3 \%$ for Cascade process 1 and increased to $68.5 \%$ for Cascade process 2. However, occupying ratios of acetic acid decreased from $96.1 \%$ to $94.3 \%$ for Cascade process 1 and to $72.6 \%$ for Cascade process 2 whereas propionic acid and butyric acid ratios increased in acidogenesis of Cascade process 2. The leachate recirculation promoted hydrolysis of substrate in Cascade process 2, where apparent hydrolysis rate constant and VS degradation ratio were higher than that of Cascade process 1.
\end{abstract}


Keywords: leachate from methanogenic process, cascade process, hydrolysis rate constant, volatile solid degradation ratio, unionized VA, ionized VA, VA spectrum 


\section{Introduction}

With some superiorities over the conventional one-phase process (Cohen et al., 1979), the two-phase anaerobic digestion process has been widely used in treatment of industrial wastewater (Bull et al., 1984), dairy-industry wastes (Ghosh et al., 1994), municipal solid wastes (Sans et al., 1995; Chugh et al., 1999) and solid food wastes (Argelier et al., 1998; Traverso et al., 2000). It was carried out in two physically separated reactors with responsibility for hydrolysis/acidogenesis and methanogenesis respectively. With the aim to accelerate degradation of complex organic compounds and obtain the maximum concentrations of intermediary products, hydrolysis/acidogenesis is recognized as a rate-limited step where the substrate consists of particles (Eastman et al., 1981). Its performance was significantly affected by environmental and operational parameters such as $\mathrm{pH}$, temperature, substrate, process configuration and concentrations of intermediaries (Veeken et al., 1999).

In the two-phase anaerobic digestion of solid waste, metabolic intermediary products such as volatile acids (VA) in the acidogenic reactor were prone to accumulate due to the absence of methanogenic microorganisms which consume the intermediaries directly (Eastman et al., 1981). According to the surface based kinetics model (Sanders et al., 2000), where it was assumed that the substrate was spherical particles and was degraded from outside, the metabolic intermediaries could easily attach onto the surface of the particles and 
prevent the microorganisms entrance for further reaction. In addition, Veeken and his workers (2000) observed that the accumulation of metabolic intermediaries such as VA restricted both methanogenesis and acidogenesis. Especially, unionized volatile acid (UVA) would inhibit not only the former (Kroeker et al., 1979), the latter (Garcia et al., 1991) but also the hydrolysis rate of particulate matter (Llabres-Luengo et al., 1988). Simultaneously, physical separation of acidogenic and methanogenic phases suppressed the syntrophic acidogenic reactions due to excessive hydrogen-forming where there was a deficiency of methanogenic microorganisms (Fox et al., 1994).

Some investigations, such as in situ removal of VA and alteration of process configurations, were conducted to alleviate the inhibition of high-concentration VA. Generally, the methods for in situ removal, which removed the excess VA physically by extraction, electrodialysis and adsorption (Sun et al., 1999; Aljundi et al., 2005; Hirata et al., 2005), were used to recover VA as products from the fermentation broth. And the attempts to alter process configurations, such as leachate recirculation, solid recycle process and cascade process, were made to ease the inhibition by providing a predominant environment for microorganisms.

Leachate recirculation, which was operated by recycling the effluent from a methanogenic process to acidogenic or hydrolysis process, can not only alleviate the inhibition of excess VA, but also establish the balance between each step in the two-phase degradation process. Veeken et al. (2000) designed a batch-wise solid state digestion (BSSD) 
setup with leachate recirculation to evaluate the effect of leachate recirculation on solid state digestion of biowaste and concluded that the apparent first order hydrolysis rate constant increased from 1.0 to $17.0 \times 10^{-3} / \mathrm{d}$ as the leachate recirculation rates increased from 1 to 100 $\mathrm{m}^{3} / \mathrm{m}^{3} / \mathrm{d}$. Moreover, Jiang et al. (2005) developed a solid recycle (SR) process with leachate recirculation from a methanogenic reactor to acidogenesis using a rotational drum fermentation system (RDFS) to evaluate the effects of leachate on acidogenic performance. Their results showed that the leachate recirculation elevated the $\mathrm{pH}$ levels and improved acidogenic performance of the solid recycle process such as increasing VA concentration and VS degradation ratio.

Another process configuration, the cascade process, which separated hydrolysis-acidogenesis into detached reactors may be appropriate to suppress inhibitions caused by high-concentration products as well. The separation of the hydrolysis and the acidogenic phase could establish the concentration gradients of $\mathrm{pH}$ and reactants for each step, hence upgrading the hydrolysis of solid particles (Jiang et al., 2003). Argelier et al. (1998) established a cascade process for food solid waste to lessen the inhibition of VA on fermentative activities. They succeeded in obtaining effluent with $42 \mathrm{~g} / \mathrm{L}$ of VA at steady-state conditions at a loading of $12.5 \mathrm{~kg}-\mathrm{COD} / \mathrm{m}^{3} / \mathrm{d}$ and a hydraulic retention time of 12.5 days. Utilizing the rotational drum fermentation system, Jiang et al. (2003) introduced a cascade process and a solid recycle process to achieve a higher TVA concentration and hydrolysis rate. 
The results indicated that the separation of hydrolysis and acidogenesis strongly affected acidogenic performance in terms of the VA constituents and the distribution of ionized and unionized VA.

The purpose of this work was to enhance the hydrolysis and acidification of solid organic waste in a cascade process with leachate recirculation by a rotational drum fermentation system. The objectives were to: (1) construct a cascade process using a rotational drum fermentation system that recycles the leachate from a methanogenic to acidogenic process, and (2) evaluate the effects of leachate on acidogenic performance via parameters such as $\mathrm{pH}$, VA production, hydrolysis rate constant and VS degradation ratio, in comparison with a single cascade process.

\section{Materials and methods}

2.1. Substrate and feeding sludge

Fresh soybean meal or Okara (approximately 20\% total solids), a food process by-product from soybean curd (Hisaki Tofu, Shimane, Japan), was used as substrates. The chemical characteristics of the soybean meal were identical to the ones shown previously by Kitamura et al. (1998).

Mesophilic anaerobic sludge from a municipal sewage treatment center (Shimane, Japan) was inoculated in the fermentors as the seeding sludge. 


\subsection{Process configuration}

The cascade process configuration is shown in figure 1. $\alpha$ represents the recirculation ratio of leachate to feeding rate for fermentors II and IV, respectively. In the case of $\alpha=0$, the process is named as Cascade process 1 whereas the process is termed Cascade process 2 as $\alpha=1$.

Each process consists of two fermentors for pseudohydrolysis and pseudoacidogenesis, respectively. Either fermentor I or II is a component of Cascade process 1. Feedstock was fed to fermentor I, and then the effluent from fermentor I was fed to fermentor II. Finally, sludge from fermentor II was excreted as an effluent of Cascade process 1. Cascade process 2 comprises fermentor III and IV. The same feedstock was fed to fermentor III, then its effluent was diluted by leachate from a methanogenic process as feedstock without loss of hydrolytic and acidogenic microorganisms fed to fermentor IV.

Figure 1.

The methanogenic fermentor (Jiang et al., 2005) was fed daily with synthetic wastewater (Chang et al., 1982) and operated at mesophilic condition with an HRT of 10 days. $\mathrm{CH}_{4}$ content in the biogas and the VA concentration in the effluent were $64-72 \%$ and $1900 \mathrm{mg} / \mathrm{L}$, respectively, whereas the TS was close to zero. The liquid fraction of the effluent obtained by centrifugation at $3000 \mathrm{rpm}$ for 3 minutes was recycled to acidogenic process as a "leachate" 
of methanogenic process.

2.3. Experimental apparatus and procedure

A rotational drum fermentation system (Jiang et al., 2002, 2003) was employed. The aluminum oxide milling balls (diameter $=30 \mathrm{~mm}$ ) were added to pseudohydrolytic fermentors ( I and III ) to occupy $10 \%$ of $3.6 \mathrm{~L}$ fermentor volume. However, to avoid the adverse effect of ball rotation on biomass growth, there were no milling balls in the pseudoacidogenic fermentor (II and IV). The RDFS and the methanogenic fermentor were both operated in an incubator at a constant mesophilic temperature $\left(36\right.$ to $\left.38{ }^{\circ} \mathrm{C}\right)$.

Prior to starting the experiments, a preheated mixture of the fresh anaerobic sludge and the substrate were inoculated into every fermentor at a weight ratio of 1:1 (anaerobic sludge to feedstock). The substrate was fed daily by the draw- and- fill method at a total HRT of 20 days for each process. Semicontinuous rotation was conducted at 30-min intervals and for 15 min throughout the experimental period, with the drum rotation at around $12 \mathrm{rpm}$.

The experiment conditions are summarized in Table 1.

Table 1

\subsection{Measurement and analysis}

Total solids (TS), pH, volatile acids, and volatile solids (VS) were determined according to the sewage test procedure (Japan Sewage Association, 1997). A capillary electrophoresis analytical system (HP, 3DCE) was employed to monitor the VA spectrum during the 
steady-state period. Biogas composition analysis was performed for $\mathrm{CH}_{4}$ and $\mathrm{CO}_{2}$ content using a gas chromatograph (SHIMADZU, GC-14A) equipped with a thermal conductivity detector (TCD).

\section{Results and discussion}

Table 2 shows the values of $\mathrm{pH}, \mathrm{pH}$ gradient, TVA, TVA gradient, ionized and unionized VA distribution, and VA spectrum for all fermentors. Table 3 shows the VS, VS gradient, VS degradation ratios and hydrolysis rate constants. The results were derived from averaging the consecutive one-month data during the steady-state period.

\subsection{VA production}

Low values of $\mathrm{pH}(4.6-5.2)$ in all fermentors indicated that the acidogenesis was prevailing. The results of fermentor I and III are the same. In comparison with the fermentor I, II, III, the $\mathrm{pH}$ value in fermentor IV increased due to leachate recirculation.

A high VA concentration (12.6-16.7 g/L) was obtained in all fermentors. The highest VA concentration $(16.7 \mathrm{~g} / \mathrm{L})$ occurred in fermentor II followed by fermentor IV $(14.5 \mathrm{~g} / \mathrm{L})$. The lowest VA concentration existed in fermentor I and III $(12.6 \mathrm{~g} / \mathrm{L})$.

As shown in tables 2 and 3, both cascade processes were favorable to establish the gradients of reactants' (substrates and products) concentration and $\mathrm{pH}$. The values of $\mathrm{pH}$ decreased from 6.5 to 4.6 in fermentors I and III, from 4.6 to 4.5 in fermentor II, and from 5.2 
to 5.1 in fermentor IV. Simultaneously, with Okara as substrates, VS content decreased from 188 to $168 \mathrm{~g} / \mathrm{L}$ in fermentors I and III, from 168 to $157 \mathrm{~g} / \mathrm{L}$ in fermentor II, and from 84 to 74 $\mathrm{g} / \mathrm{L}$ in fermentor IV. As a result of VS degradation, the VA concentration increased in all fermentors, from 0 in Okara to $12.6 \mathrm{~g} / \mathrm{L}$ in fermentor I and fermentor III, from 12.6 to 16.7 $\mathrm{g} / \mathrm{L}$ in fermentor II, and from 7.3 (averaging the VA concentration of fermentor III and the leachate ) to $14.5 \mathrm{~g} / \mathrm{L}$ in fermentor IV. The greater change of VA concentration in fermentor IV than that in fermentor II was due to the addition of leachate lowered VA concentration and heightened the value of $\mathrm{pH}$ of feedstock from fermentor III, thus enhancing acidogenesis. This phenomenon implied the adverse effects of products on the acidogenesis.

From the viewpoint of VA generation, Cascade process 2 with leachate recirculation was more favourable than Cascade process 1 with no addition.

VA generated from fermentor I $(12.6 \mathrm{~g} / \mathrm{L})$ and fermentor II $(4.1 \mathrm{~g} / \mathrm{L})$ provided $75 \%$ and $25 \%$ VA respectively for Cascade process 1 . Fermentor III ( $6.3 \mathrm{~g} / \mathrm{L}, 43.4 \%$ total process VA) contributed less VA to Cascade process 2 than fermentor IV $(7.2 \mathrm{~g} / \mathrm{L}, 49.7 \%$ total process VA). Compared with fermentor II, higher VA contribution ratio of fermentor IV was also due to the recirculation of leachate from the methanogenic process. It helped elevate the $\mathrm{pH}$ level (4.6 to 5.2) approaching the optimum (6.0-6.5) proposed by Kisaalita et al. (1987) and reduce the VA concentration of influent for fermentor IV. These phenomena proved that the leachate promoted the acidogenesis. 
Table 2

VA can exist in solution in two principal forms: unionized VA (UVA) and ionized VA. The concentrations of UVA were calculated based on the total VA (TVA, g/L) by the following equilibrium expression (Bujoczek et al., 2000):

$$
U V A=V A\left(10^{(p K a-p H)}\right) /\left(1+10^{(p K a-p H)}\right)
$$

where $\mathrm{pK}_{\mathrm{a}}$ is the dissociation constant value of the acids in water, $\mathrm{pK}_{\mathrm{a}}=4.762$ for acetic acid at $35^{\circ} \mathrm{C}$ (Weast, 1981).

The distributions of ionized and unionized VA were given in Table 2. The occupying ratios of ionized VA increased as $\mathrm{pH}$ increased. The highest ratio of ionized VA to total VA was obtained in fermentor IV (68.5\% TVA), followed by fermentors I and III (40.5\% TVA), whereas the lowest ratio occurred in fermentor II (35.3\% TVA). It can be seen that the results were affected strongly by the leachate recirculation. The occupying ratios of ionized VA in Cascade process 2 were elevated by manipulating the $\mathrm{pH}$ levels after leachate recirculation.

The observed VA spectrum is shown in Table 2. Acetic acid was predominant in fermentors I, II and III, followed by succinic acid, while no butyric acid and propionic acid was detected. Due to the leachate recirculation, no succinic acid was detected whereas propionic acid and butyric acid were observed in fermentor IV. Other volatile acids were measured at negligible concentrations.

The effect of leachate in this study is revealed by the shift in the VA spectra, in which the 
occupying ratio of acetic acid was decreased from $94.3 \%$ to $72.6 \%$ in Cascade process 2 . Existence of propionic and butyric acids implied that the leachate recirculation accelerated the degradation of long-chain VA such as succinic acid. Higher propionic acid content observed in Cascade process 2 would be fatal for methanogenic process. The decreased occupying ratio of acetic acid in fermentor IV (72.6\%) demonstrated that the higher ionized VA $(68.5 \%$ TVA) was prone to be converted to biogas by methanogenic microorganisms. In addition, the absence of amino acids from hydrolysis of protein in all fermentors can be explained by the presence of carbohydrates, which suppress the protein degradation (Yu et al., 2001).

\subsection{Hydrolysis rate constant}

Based on first-order hydrolysis kinetics, the hydrolysis phase can be expressed using Equation (2) (Borzacconi et al., 1997).

$$
\frac{d S}{d t}=-K_{h} S
$$

where $\mathrm{K}_{\mathrm{h}}$ is the particulate matter hydrolysis rate constant (per day), and $\mathrm{S}$ is the substrate concentration in solid phase (g-VS/L).

Alternatively, Equation (2) can be transformed into Equation (3) by a definite integral:

$$
\ln \left(\frac{S_{0}}{S_{T}}\right)=K_{h} T
$$

where $\mathrm{S}_{0}$ is the initial substrate concentration $(\mathrm{g}-\mathrm{VS} / \mathrm{L})$ at $\mathrm{T}=0 ; \mathrm{S}_{\mathrm{T}}$ is the substrate concentration in fermentor withdrawal at time $\mathrm{T}(\mathrm{g}-\mathrm{VS} / \mathrm{L})$; and $\mathrm{T}$ is the reaction time (day).

In the steady state operation, the microorganism is in the exponential growth period, therefore, 
the reaction time is equivalent to the HRT.

Table 3

Substituting the experimental data into Equation (3), $\mathrm{K}_{\mathrm{h}}$ for each fermentor was calculated (Table 3). The highest $\mathrm{K}_{\mathrm{h}}\left(12.4 \times 10^{-3} / \mathrm{d}\right)$ in fermentor IV was because of the leachate recirculation. The second highest value of $\mathrm{K}_{\mathrm{h}}\left(11.3 \times 10^{-3} / \mathrm{d}\right)$ occurred in fermentor I and III, whereas the lowest value $\left(6.8 \times 10^{-3} / \mathrm{d}\right)$ occurred in fermentor II. The lowest value in fermentor II was because of the adverse effect of high products concentration on hydrolysis.

The leachate recirculation in Cascade process 2 elevated the $K_{h}$ of fermentor IV $\left(12.4 \times 10^{-3}\right.$ /d) in contrast to the one in fermentor II in Cascade process $1\left(6.8 \times 10^{-3} / \mathrm{d}\right)$.

Apparent hydrolysis rate constants $\left(\mathrm{K}_{0}, \mathrm{~K}_{0}{ }^{\prime}\right)$ of two processes were deduced by Equation (4) for Cascade process 1 and (5) for Cascade process 2.

$$
K_{0}=\frac{1}{T_{0}}\left(K_{1} T_{1}+K_{2} T_{2}\right)
$$

where $\mathrm{T}_{0}$ is the apparent HRT for Cascade process 1 (day); $\mathrm{K}_{1}$ and $\mathrm{K}_{2}$ are the hydrolysis rate constants for fermentor I and II (per day), respectively; and $\mathrm{T}_{1}$ and $\mathrm{T}_{2}$ are the HRTs for fermentor I and II (day), respectively.

$$
K_{0}{ }^{\prime}=\frac{1}{T_{0}{ }^{\prime}}\left(K_{3} T_{3}+K_{4} T_{4}\right)
$$

where $\mathrm{T}_{0}$ ' is the apparent HRT for Cascade process 2 (day); $\mathrm{K}_{3}$ and $\mathrm{K}_{4}$ are the hydrolysis rate constants for fermentor III and IV (per day), respectively; $\mathrm{T}_{3}$ and $\mathrm{T}_{4}$ are the HRTs for fermentor III and IV (day), respectively. 
$\mathrm{T}_{0}$ and $\mathrm{T}_{0}$ ' can be deduced by Equation (6) and (7).

$$
\begin{aligned}
& T_{0}=\frac{1}{1+\alpha} T_{1}+T_{2} \\
& T_{0}{ }^{\prime}=\frac{1}{1+\alpha} T_{3}+T_{4}
\end{aligned}
$$

Where $\alpha$ is the recirculation ratio of leachate to feeding rate for fermentor II $(\alpha=0)$ and IV $(\alpha=1)($ Fig. 1).

According to the experimental conditions, $\mathrm{K}_{0}$ of $9.0 \times 10^{-3} / \mathrm{d}$ and $\mathrm{K}_{0}$ ' of $15.8 \times 10^{-3} / \mathrm{d}$ for the two processes were obtained by substitution of the experimental data into Equation (4) and (5). The first order hydrolysis rate constant of Cascade process 2 was raised remarkably by the leachate recirculation. This result indicated that the leachate recirculation strongly affected the cascade process.

3.3. VS degradation ratio

The VS degradation ratio ( $\mathrm{R}, \%$ ) was determined by Equation (8).

$$
R=\frac{S_{\text {in }}-S_{\text {out }}}{S_{\text {in }}} \times 100
$$

where $\mathrm{R}$ is the VS degradation ratio (\%); $\mathrm{S}_{\text {in }}$ is the initial substrate concentration ( $\left.\mathrm{g}-\mathrm{VS} / \mathrm{L}\right)$; and $\mathrm{S}_{\text {out }}$ is the substrate concentration of withdrawal from fermentors ( $\left.\mathrm{g}-\mathrm{VS} / \mathrm{L}\right)$.

Substituting the experimental parameters of each fermentor to Equation (8), $\mathrm{R}$ of each fermentor can be calculated and was shown in Table 3. The highest VS degradation ratio (11.7\%) was observed in fermentor IV. The second highest VS degradation ratio (10.6\%) was found in fermentors I and III. The highest R of fermentor IV was owing to the leachate recirculation. $\mathrm{R}$ of fermentor II was lower than that in fermentor I due to the lower $\mathrm{pH}$ 
gradient and the inhibition resulting from excessive VA concentration.

The apparent VS degradation ratios of the two processes can be calculated by Equation (9) for Cascade process 1 and Equation (10) for Cascade process 2.

$$
R_{0}=R_{1}+R_{2}-R_{1} R_{2}
$$

where $\mathrm{R}_{0}$ is the apparent VS degradation ratio for Cascade process $1(\%) ; \mathrm{R}_{1}, \mathrm{R}_{2}$ are the VS degradation ratios for fermentors I and II (\%), respectively.

$$
R_{0}{ }^{\prime}=R_{3}+R_{4}-R_{3} R_{4}
$$

where $\mathrm{R}_{0}$ ' is the apparent VS degradation ratio for Cascade process $2(\%) ; \mathrm{R}_{3}, \mathrm{R}_{4}$ are the VS degradation ratios for fermentors III and IV (\%), respectively.

Substituting the values of $R_{1}, R_{2}, R_{3}$ and $R_{4}$ to Equation (9) and (10), $R_{0}$ of $16.5 \%$ for Cascade process 1 and $\mathrm{R}_{0}$ ' of $21.1 \%$ for Cascade process 2 were obtained. The VS degradation ratio for Cascade process 2 was higher than that of Cascade process 1.

Based on the results of VA production, hydrolysis rate constants and VS degradation ratios, it is shown that the leachate recirculation promoted the hydrolysis and upgraded acidogenic performance in Cascade process. The VA concentration, the VS degradation ratio and the hydrolysis rate constant of Cascade process 2 were higher than that of Cascade process 1 . It is likely that the recirculation of leachate raised the $\mathrm{pH}$ levels due to its neutralization, and, in turn, upgraded the distribution of ionized and unionized VA. In 
comparison with the solid recycle process with leachate recirculation developed by Jiang et al. (2005), the cascade process was favorable according to hydrolysis rate constants and VS degradation ratios, which were increased from 14.4 to $15.8 \times 10^{-3} / \mathrm{d}$ and from 19.4 to $21.1 \%$, respectively.

\section{Conclusions}

In the acidogenic process of solid organic waste, the volatile acids were prone to accumulate and inhibit both hydrolysis and acidogenesis. The cascade process of a rotational drum fermentation system with methanogenic leachate recirculation alleviated the inhibition by establishing the gradients of $\mathrm{pH}$ and product concentration for each step. The leachate recirculation elevated $\mathrm{pH}$ levels, and in turn, influenced the distribution of ionized and unionized volatile acid. Simultaneously, VA constituents were affected by alteration of process configuration. The occupying ratio of acetic acid decreased whereas propionic acid and butyric acid increased with leachate recirculation. Our results suggest that the cascade process with methanogenic leachate recirculation assist to improve the acidogenic performance of solid organic waste. 


\section{References}

Aljundi, I.H., Belovich, J.M., Talu, O., 2005. Adsorption of lactic acid from fermentation broth and aqueous solutions on Zeolite molecular sieves. Chemical Engineering Science 60, 5004-5009.

Argelier, S., Delgenes, J. -Ph., Moletta, R., 1998. Design of acidogenic reactors for the anaerobic treatment of the organic fraction of solid food waste. Bioprocess Engineering 18, 309-315.

Borzacconi, L., López, I., Anido, C., 1997. Hydrolysis constant and VFA inhibition in acidogenic phase of MSW anaerobic degradation. Water Science and Technology 36 (6-7), 479-484.

Bujoczek, G., Oleszkiewicz, J., Sparling, R., Cenkowski, S., 2000. High solid anaerobic digestion of chicken manure. Journal of Agricultural Engineering Research 76, 51-60.

Bull, M.A., Sterritt, R.M., Lester, J.N., 1984. An evaluation of single- and separated-phase anaerobic industrial wastewater treatment in fluidized bed reactors. Biotechnology and Bioengineering 26, 1054-1065.

Chang, J.E., Noike, T., Matsumoto, J., 1982. Effect of retention time and feed substrate concentration on methanogenesis in anaerobic digestion. Transaction of the Japanese Society of Civil Engineering 320, 67-76.

Chugh, S., Chynoweth, D.P., Clarke, W., Pullammanappallil, P., Rudolph, V., 1999. 
Degradation of unsorted municipal solid waste by a leach-bed process. Bioresource Technology 69, 103-115.

Cohen, A., Zoetemeyer, R.J., Van Deursen, A., Van Andel, J.G., 1979. Anaerobic digestion of glucose with separated acid production and methane formation. Water Research 13, $571-580$.

Eastman, P.A., Rico, J.L., Polanco, F. Fdz., 1981. Anaerobic treatment of cheese whey in a two-phase reactor. Environmental Technology 12, 355-362.

Fox, P., Pohland, F.G., 1994. Anaerobic treatment applications and fundamentals: substrate specificity during phase separation. Water Environment Research 66 (5), 716-724.

Garcia, J.B., Ibanez, R.G., Ghawas, Hani.A.Al, Sandall, O.C., 1991. On the effect of basicity on the kinetics of $\mathrm{CO}_{2}$ absorption in tertiary amines. Chemical Engineering Science 46 (11), 2927-2931.

Ghosh, S., Fukushi, K., Liu, T., Kalra, S., Mariger, C., Hansen, C., Debirk, L., Bupp, S., Christensen, J., Sargent, S., Millar, R., 1994. Pilot plant for biomethanation of dairy-industry wastes. Proceedings of the Sixth National Bioenergy Conference, Reno/ Sparks, Nevada.

Hirata, M., Gao, M., Toorisaka, E., Takanashi, H., Hano, T., 2005. Production of lactic acid by continuous electrodialysis fermentation with a glucose concentration controller. Biochemical Engineering Journal 25, 159-163. 
Japan Sewage Association 1997. pH measurement, 110-111; Total Solid and Volatile Solid measurement, 296-297; Volatile Acids measurement, 300-304; Sewage Test Procedure, Japan Sewage Association, Tokyo (In Japanese).

Jiang, W.Z., Kitamura, Y., Ishizuka, N., Shiina, T., 2002. A rotational drum fermentation system for dry methane fermentation (2): Effect of hydraulic retention time (HRT) and stirring media in fermentor on acidogenic process. Journal of the Society of Agricultural Structures, Japan 33 (3), 189-196.

Jiang, W.Z., Kitamura, Y., Ishizuka, N., Shiina, T., 2003. A rotational drum fermentation system for dry methane fermentation (3): Effect of process configuration on acidogenic process. Journal of the Society of Agricultural Structures, Japan 34 (2), 91-100.

Jiang, W.Z., Kitamura, Y., Li, B., 2005. Improving acidogenic performance in anaerobic degradation of solid organic waste using a rotational drum fermentation system. Bioresource Technology 96,1537-1543.

Kisaalita, W.S., Pinder, K.L., 1987. Acidogenic fermentation of lactose. Biotechnology and Bioengineering 30, 88-95.

Kitamura, Y., Tagawa, A., Nakao, S., Hansen, C.L., 1998. Liquefaction for anaerobic treatment of soybean meal. Journal of the Society of Agricultural Structures, Japan 29 (2), 69-74.

Kroeker, E.J., Schulte, D.D., Sparling, A.B., Lapp, H.M., 1979. Anaerobic treatment process stability. Journal of Water Pollution Control Federation 51 (4), 718-727. 
Llabres-Luengo, P., Mata-Alvarez, J., 1988. The hydrolytic step in a dry digestion system. Biological Wastes 23, 25-37.

Sanders, W.T.M., Geerink, M., Zeeman, G., Lettinga, G., 2000. Anaerobic hydrolysis kinetics of particulate substrates. Water Science Technology 41 (3), 17-24.

Sans, C., Mata-Alvarez, J., Cecchi, F., Pavan, P., Bassetti, A., 1995. Volatile fatty acids production by mesophilic fermentation of mechanical-sorted urban organic wastes in a plug-flow reactor. Bioresource Technology 51, 89-96.

Sun, Y., Li, Y.-L, Bai, S., Hu, Z.-D., 1999. Modeling and simulation of an in situ product removal process for lactic acid production in an airlift bioreactor. Industrial and Engineering Chemistry Research 38(9), 3290-3295.

Traverso, P., Pavan, P., Bolzonella, D., Innocenti, L., Cecchi, F., Mata-Alvarez, J., 2000. Acidogenic fermentation of source separated mixtures of vegetables and fruits wasted from supermarkets. Biodegradation 11, 407-414.

Veeken, A., Hamelers, B., 1999. Effect of temperature on hydrolysis rates of selected biowaste components. Bioresource Technology 69, 249-254.

Veeken, A., Hamelers, B., 2000. Effect of substrate-seed mixing and leachate recirculation on solid state digestion of biowaste. Water Science and Technology 41(3), 255-262.

Weast, R.C. (Ed.), 1981. Handbook of Chemistry and Physics. CRC Press Inc. Boca Raton, FL, USA, p. D-145. 
Yu, H.Q., Fang Herbert, H. P., 2001. Acidification of mid- and high-strength dairy wastewaters. Water Research 35(15): 3697-3705. 


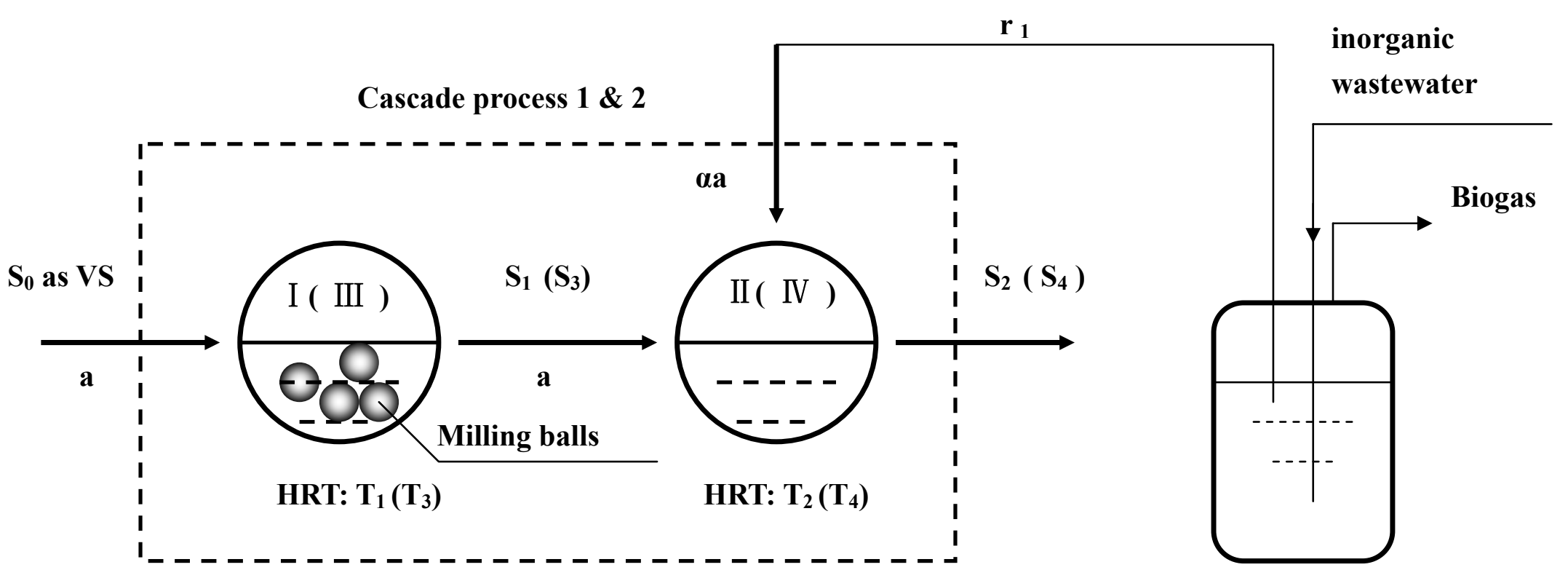

Methanogenic fermentor

Fig. 1 Cascade process configurations for acidogenesis. a (g/d): feeding rate of Okara; $\alpha(-)$ : recirculation ratio of leachate to feeding rate for fermentor II and IV, respectively; $S$ (g/L): VS concentration in each stream; $r_{1}(-)$ : recirculation ratio of leachate to volume of corresponding fermentor content for Cascade process. 
Table 1

Experimental conditions

\begin{tabular}{|c|c|c|c|c|}
\hline $\begin{array}{l}\text { Acidogenic } \\
\text { process }\end{array}$ & $\begin{array}{l}\text { Fermentor } \\
\text { No. }\end{array}$ & $\begin{array}{l}\text { HRT } \\
\text { (days) }\end{array}$ & Feeding rate $(/ \mathrm{d})$ & Loading rate (/L/d) \\
\hline \multirow[t]{2}{*}{ Cascade 1} & I & 10 & 120 g Okara & 100 g Okara \\
\hline & II & 10 & $120 \mathrm{~g}$ sludge from $\mathrm{I}$ & $100 \mathrm{~g}$ sludge from $\mathrm{I}$ \\
\hline \multirow[t]{2}{*}{ Cascade 2} & III & 10 & 120 g Okara & 100 g Okara \\
\hline & IV & 10 & $\begin{array}{l}120 \mathrm{~g} \text { sludge from } \mathrm{III}+120 \mathrm{~g} \text { leachate } \\
\text { from methane fermentor }\end{array}$ & $\begin{array}{l}50 \mathrm{~g} \text { sludge from III }+50 \mathrm{~g} \text { leachate } \\
\text { from methane fermentor }\end{array}$ \\
\hline \multicolumn{2}{|c|}{ Methane fermentor } & 10 & $300 \mathrm{~g}$ inorganic wastewater $+3 \mathrm{~g}$ acetic acid & $100 \mathrm{~g}$ inorganic wastewater $+1 \mathrm{~g}$ acetic acid \\
\hline
\end{tabular}


Table 2

Steady-state parameters for two processes

\begin{tabular}{|c|c|c|c|c|c|c|c|c|c|c|c|c|c|}
\hline \multirow{2}{*}{$\begin{array}{c}\text { Acidogenic } \\
\text { process }\end{array}$} & \multirow{2}{*}{$\begin{array}{c}\text { Fermentor } \\
\text { No. }\end{array}$} & \multicolumn{2}{|c|}{$\mathrm{pH}(-)$} & \multirow{2}{*}{$\begin{array}{c}\mathrm{pH} \\
\text { gradient } \\
(-)\end{array}$} & \multicolumn{2}{|c|}{ TVA $(\mathrm{g} / \mathrm{L})$} & \multirow{2}{*}{$\begin{array}{c}\text { TVA } \\
\text { gradient } \\
(\mathrm{g} / \mathrm{L})\end{array}$} & \multicolumn{2}{|c|}{ VA Distribution } & \multicolumn{4}{|c|}{ VA Spectrum } \\
\hline & & in & out & & in & out & & $\begin{array}{l}\text { Ionized } \\
\text { VA (\%) }\end{array}$ & $\begin{array}{c}\text { Unionized } \\
\text { VA (\%) }\end{array}$ & $\begin{array}{c}\text { Acetic } \\
\text { acid (\%) }\end{array}$ & $\begin{array}{c}\text { Propionic } \\
\text { acid (\%) }\end{array}$ & $\begin{array}{c}\text { Butyric } \\
\text { acid (\%) }\end{array}$ & $\begin{array}{l}\text { Succinic } \\
\text { acid (\%) }\end{array}$ \\
\hline \multirow[t]{2}{*}{ Cascade 1} & I & $6.5 \pm 0.1$ & $4.6 \pm 0.1$ & 1.9 & 0 & $12.6 \pm 0.2$ & 12.6 & $40.5 \pm 1.2$ & $59.5 \pm 1.5$ & 96.1 & ND & ND & 3.9 \\
\hline & II & $4.6 \pm 0$ & $4.5 \pm 0$ & 0.1 & $12.6 \pm 0.2$ & $16.7 \pm 0$ & 4.1 & $35.3 \pm 0.6$ & $64.7 \pm 2.4$ & 94.3 & ND & ND & 5.7 \\
\hline \multirow[t]{2}{*}{ Cascade 2} & III & $6.5 \pm 0.1$ & $4.6 \pm 0.1$ & 1.9 & 0 & $12.6 \pm 0.2$ & 12.6 & $40.5 \pm 1.1$ & $59.5 \pm 0.8$ & 96.1 & ND & ND & 3.9 \\
\hline & IV & $5.2 \pm 0$ & $5.1 \pm 0$ & 0.1 & $7.3 \pm 0.3$ & $14.5 \pm 0.8$ & 7.2 & $68.5 \pm 1.3$ & $31.5 \pm 1.4$ & 72.6 & 8.2 & 19.2 & ND \\
\hline
\end{tabular}

Note: ND represents undetectable. 
Table 3

Steady-state parameters for two processes

\begin{tabular}{ccrcccc}
\hline \multirow{2}{*}{$\begin{array}{c}\text { Acidogenic } \\
\text { process }\end{array}$} & $\begin{array}{c}\text { Fermentor } \\
\text { No. }\end{array}$ & \multicolumn{2}{c}{ in } & out & VS $(\mathrm{g} / \mathrm{L})$ & gradient \\
\cline { 3 - 4 } & & & & & $\begin{array}{c}\text { Hydrolysis } \\
\text { rate constant } \\
\left(\mathrm{K}_{\mathrm{h}}, 10^{-3} / \mathrm{d}\right)\end{array}$ & $\begin{array}{c}\text { VS } \\
\text { degradation } \\
\text { ratio (R, \%) }\end{array}$ \\
\hline Cascade 1 & I & $188.0 \pm 5.3$ & $168.0 \pm 4.8$ & 20.0 & 11.3 & 10.6 \\
& II & $168.0 \pm 4.8$ & $157.0 \pm 3.7$ & 11.0 & 6.8 & 6.6 \\
Cascade 2 & III & $188.0 \pm 5.3$ & $168.0 \pm 4.8$ & 20.0 & 11.3 & 10.6 \\
& IV & $84.0 \pm 2.3$ & $74.2 \pm 2.1$ & 9.8 & 12.4 & 11.7 \\
\hline
\end{tabular}

